\title{
Teaching at a medical university and modernization of the higher education system
}

\author{
Vladimir I. Torshin ${ }^{1}$, Dmitriy S. Sveshnikov ${ }^{1}$, Elena B. Yakunina ${ }^{1}$, Zarina V. Bakaeva ${ }^{1}$, \\ Yuri P. Starshinov ${ }^{1}$, Olga V. Mankaeva ${ }^{1}$, Tatiana V. Kivlenok ${ }^{2}$ and Mariam R. Arpentieva ${ }^{3 *}$ \\ ${ }^{1}$ Medical Institute Peoples' Friendship University of Russia, \\ 8, Miklukho-Maklay str., Moscow, 117198, \\ Russian Federation \\ ${ }^{2}$ M.M. Speranskiy Law Institute, A.G. and N.G. Stoletovs Vladimir State University \\ 8, Studencheskaya str., Vladimir, 600005 \\ Russian Federation \\ ${ }^{3}$ Center for Psychological, Pedagogical, Medical and Social Assistance "Assistance" \\ 44, Dostoevskiy str., Kaluga, 248000 \\ Russian Federation
}

Received: January 13, 2020. Revised: July 22, 2020. 2nd Revised: October 12, 2020. Accepted: October 15, 2020. Published: October 16, 2020.

\begin{abstract}
The relevance of the research is determined by changes in the forms and content of education in the field of training medical workers, including in the context of the accreditation procedures for medical universities and colleges, as well as the accreditation of graduates themselves. The article focuses on the issues of improving the quality of teaching in a medical school of courses responsible for the educational and professional results of students. The aim of the study is to comprehend the structure and content, didactic means of organizing the training of future doctors and nurses. The theoretical basis for the study of this problem is the activity approach, which makes it possible to compare and study the processual and substantive aspects of the pedagogical activity of a teacher of a medical university or college in the context of the educational results of its graduates. The article reflects the problems of training and education of medical workers, describes different types of teacher activities. These types of activities are integrated into the whole process of teaching the discipline, focused on improving the educational and professional results of students. It is especially necessary the development on the basis of the system-activity approach and the widespread introduction of new methodological approaches and the educational, methodological and other manuals that provide them, ensuring the harmony of the processes of interiorization and externalization of the knowledge, skills, value orientations necessary for a person as a professional, partner and personality.
\end{abstract}

Keywords - activity approach, competence, integrative approach, contents of activity, psychological structure of activity, teaching activities.

\section{INTRODUCTION}

$\mathrm{T}$ HE development and implementation of new state standards in the educational process at a medical college or university is associated with the introduction of formal and substantive changes in teaching and upbringing. Great attention now the focus is on the formation and development of competencies that provide a more or less conscious organization by a specialist of his activities, her various types of activities within the framework of changes in the social and professional context [1].

Scientific understanding of the educational process in a medical college or university, pedagogical and methodological literature demonstrates that the teacher performs a number of basic actions (E.G. Bastrakova, N.M. Breshchanova, R. Donley, V.I. Flaherty, I.V. Kashirtseva, G.E. Mintakhanova, L.N. Shulgin, O.V. Vasilyeva and etc.). He or she introduces students to new material (knowledge that is part of the competence). It also offers samples, models, algorithms, schemes (new skills that are part of competencies). He / she explains the methods and approaches to solving various educational and professional practical problems (the use of competencies in their response to the value orientations of a specialist). It carries out extensive and ongoing activities to monitor and evaluate the learning outcomes of students in the study group [2]. However, the teacher does not always build a system of pedagogical conditions for each student to understand the actions he performs and medical activities in 
general. Therefore, many characteristics of the actions and activities of a health worker remain unclear. In the course of solving various theoretical and practical educational and professional problems, much remains for the student "closed", poorly perceived, difficult to use and entailing mistakes. Therefore, many students tend not so much to understand, but to remember, which leads to psychophysiological and other overloads and deforms the attitude towards oneself and professional activity. This also affects the results and the process of teaching and education, on the content and development of their educational and general motivation, psychophysiological and spiritual health, etc.

Teachers of colleges and universities often have problems organizing student activities if they are not teachers in terms of their basic education [3]. Many modern domestic and foreign researchers speak about this. Without high-quality psychological and pedagogical training and retraining of a university teacher to train and educate students as future doctors (professionals), as employees (partners) and as individuals, it is impossible to achieve high educational results of students defined in the new state standards of a medical university [4]. Unfortunately, medical teachers often consider the professional activity of students as a certain sum of individual actions, stages or steps that can be presented in the form of an algorithm that includes a set of skills and knowledge. Sometimes they present it in the form of an instruction or a memo indicating to the student what to do when the period for solving real professional problems comes [3]. Teachers often believe that training is the transfer of ready-made knowledge and skills to students, so they develop their professional competencies based on the algorithms and models of different types of professional activity that they have. But this happens without students understanding the universal, including moral, spiritual foundations of activity: its structural stages and components. At the same time, the teacher usually does not teach students to organize professional activities each time in different ways in accordance with the social and professional situation.

\section{METHODOLOGICAL PROBLEMS OF RESEARCH}

The new methodology for the formation of educational standards in medical colleges and universities is the activity approach [5]. The development and application of accreditation of a medical institution, educational institution and graduates and employees of these institutions is carried out in order to assess their ability to carry out professional activities. All this requires a qualitative and formal reorganization of the teacher's pedagogical activities. Accreditation is aimed at achieving each student of educational results of the planned level, in accordance with the requirements of modern medicine (its technological, moral and other aspects), society and the state. Achieving this goal requires systemic transformations in the field of training teachers for training and educating future health workers. The development and integration of innovative and traditional approaches to the organization of pedagogical activities, advanced training and reorientation of teachers of medical colleges and universities is becoming relevant.

In the works of foreign authors in the field of medical education over the past decades, the main goal is to provide a teacher with the quality of educational results of students of medical colleges and universities in the process of education and upbringing. researchers base the solution to this problem with improving the professional work of a teacher [6], with new (innovative, "greenfield") educational technologies [7], as well as with educational and methodological complexes aimed at the formation and development of competencies in the educational process, in practice and during periods entering the profession and retraining in the context of real activity in a health care institution [8].

Analysis of research shows the relevance of the development of concepts such as mental models and schemes, technologies of design (design), integration (consolidation), reflection (restructuring), indicative bases of action (schemes and scripts of professional activity, including knowledge about the subject and the ability to act with it, that is, in fact, a detailed structure of competence), etc. [9].

In domestic studies, such methods of optimizing the formation and development of competencies as tables and structural-logical diagrams, models and projects, etc., are noted. The study of the formal and content characteristics of these models and diagrams makes it possible to conclude that they are only illustrative examples of specific subject knowledge. and some "methodological instructions" developed by specific specialists. Most often, there is no systemic understanding of what is happening: many researchers choose the forms of generalization of the research results and experience of teachers in the field of training doctors and nurses "at their own discretion." The systemic foundations of the object under study are not disclosed, are not updated.

In domestic psychological and pedagogical research on the basis of the cultural-historical theory of assimilation of social experience (L.S. Vygotskiy, P. Ya.Galperin, I.I. Ilyasov, A.N. Leontiev, N.N. Nechaev, N.F. Talyzina, A. I. Podolskiy, Z.A. Reshetova, etc.) scientists and teachers determine the content of pedagogical activity, which implements in the educational process in the concept of ideas about activity. In their opinion, the educational and professional activity of a student should correspond to the form and content of training and education of the future professional $[10 ; 11 ; 12 ; 13 ; 14 ; 15 ; 16]$.

The teacher's understanding of the psyche as an orientation activity allows organizing the study of educational material, relying on the indicative foundations of the activity itself, and not on the current abilities and level of development of students. The teacher's understanding of the laws of development and functioning of the psyche (such as the presence of a zone of proximal development, the phenomena of interiorization and exteriorization, individuality and uneven development, the formation of the psyche in activity, etc.) makes it possible to organize training in the context of the 
targeted development of the readiness and ability of students to build their own indicative activities and assign competencies formed as a result of orienting activities of other people (including in the context of "metacognitive" schemes and heuristics). When mastered, this activity is automated and turns into a mental image. These images guide the student in practical activities [5]. So creativity becomes, in fact, a permanent element of labor, ensuring its efficiency and productivity.

On the basis of the activity approach, a number of studies were carried out, educational technologies were developed that implement the processes of interiorization and exteriorization: self-organization of activity. Scientists have proposed a systemic organization of the structure and content of the object under study, a systemic organization of the structure and content of activity using special means of self-organization knowledge, self-management of knowledge, organization of educational and research activities of the student, etc. [5; 13].

At present, specialists with medical education are being trained in the world according to two models - Anglo-Saxon and German. The first is practiced in the USA, Canada, England. It includes four cycles: general pre-medical higher education; general medical education; medical postgraduate education and further education, that is, advanced training. The task of general to medical medical higher education is training in natural sciences. To be admitted to medical school, applicants must pass a competitive selection. In addition to the certificate competition, most medical schools conduct testing of applicants. General medical education programs in AngloSaxon countries vary significantly. A prerequisite for admission to independent practice is residency. Upon completion of the residency, doctors continue their education and periodically improve their qualifications. In general, the preparation of a qualified doctor in these countries takes from 11 to 14 years, and in some areas (cardiac surgery, neurosurgery, psychiatry, and others) - even more.

The second model is considered to be quite effective, but it is less standardized compared to the Anglo-Saxon model. A prerequisite for admission to the Faculty of Medicine is a twoyear program "Abitour", where general humanitarian disciplines are studied, two foreign languages. The duration of study at the Faculty of Medicine is six years. To obtain admission to independent practice in Germany, 11 years are required, subject to passing the exam to obtain licenses. At the same time, within 4.5-5.5 years, the applicant must work as a trainee and doctor's assistant. In France, training lasts 6 years. Students take a certification exam, which includes theoretical and practical questions. The period of postgraduate education in France is called an internship, the duration of which depends on specialization and ranges from two to six years. After completing the internship, specialists receive a certificate that gives them the right to independent practice. Despite some differences, differences, in general, in the construction of the system of medical education all over the world, there is a general tendency of the trend: in the structure, duration of study, conditions of admission to medical organizations, education and admission to independent professional activity.

According to the recommendations of the World Federation for Medical Education (WFME), basic medical education (preclinical and clinical), postgraduate medical education (residency or specialization) and continuous professional development (advanced training of doctors) are distinguished. Moreover, each model is built taking into account national characteristics and requirements of the country's health care system.

What is the reason for such a thorough preparation, in addition to the complexity of the knowledge and skills of the future specialist? Even Hippocrates noted that in order to be a true and useful doctor and achieve accurate knowledge in medicine, a person needs to fulfill several conditions: innate talent, good upbringing, high and pure morality, study of medicine from a very young age in a well-known and good school, love for their science and its difficult pursuits in the significant time.

Being inherently one of the most difficult and important professions of the "man-to-man" class, the features of this profession manifest themselves even at the stage of training, namely, the profession of a doctor requires a very long professional training. You can get this profession in specialized medical universities / institutes that have, at times, a century-old history, are famous throughout the country, and sometimes the whole world. The professional training of a doctor presupposes a fundamental medical education, along with which a health professional has the opportunity and, as a rule, the requirement to specialize in a particular field of medicine. The education of a doctor, like a number of other socially oriented professions, presupposes the constant improvement of one's competencies, through the means of taking advanced training courses and specializations.

Not every person can be a doctor due to their personal characteristics. In Russia, about $30 \%$ of medical graduates do not go to work in medicine at all. This means that initially they were seriously mistaken in choosing a profession or simply needed to get a higher education. In some cases, they are scared off by the responsibility of the profession and its high risk, especially in specialties of the surgical profile. Another $30 \%$ of graduates, although they then work in medical institutions, are often "casual people", without an appropriate calling. In the absence of competence, such a doctor not only does not benefit the patients, but can also do a lot of harm. And only $30 \%$ of students under certain conditions can make good doctors, but we don't need bad and mediocre ones. Therefore, the task arose - to increase the percentage of students who go to medical colleges and universities, knowing full well that they want to become nurses, doctors, pharmacists, and who are ready and able to master the profession, its competencies and values, at the level, corresponding to modern. The task was also to develop approaches and methods of training and education, which could smooth out the disproportions and lack of "vocation" in 
the future employee.

Medicine is the science of human health and disease, art is the art of healing and the art of interacting with a patient, and a craft, when some approaches may not be individual, but standard. However, all over the world, standards are set not for medical technologies (there are clinical guidelines for this), but for the results of medical interventions. The doctor must have not only the necessary knowledge, skills and abilities, but also have a certain set of human qualities (values) that are manifested from childhood and are formed throughout life (attention, nobility, culture, mercy, good attitude to people, the ability to listen to another person, etc. etc.). Therefore, it is important to create a special system of preliminary testing of applicants in the form of an advising system for the presence of the qualities required by a future doctor; it is also important to create a system for monitoring the success of students in the process of studying at a college or university and supplement it with accreditation upon graduation from college or university. As a result of the application of such a system for assessing the competencies and qualities of a specialist as a person, a partner and a professional, appropriate recommendations can be given to him and the educational and health care institution, corrective and development programs can be created, etc.

When entering, it is advisable to take into account the dynastic aspects, which will allow discussing professional and ethical issues in the family circle, using the literature and medical experience accumulated over many years, etc. Universities and colleges should have a substantiated government assignment of how many and which doctors to train. Foreign experts believe that in addition to providing medical students with the necessary knowledge and skills of a nurse / doctor / pharmacist in accordance with accepted international educational standards, students need to develop clinical thinking. Such thinking (understanding) will allow them to more objectively and systematically assess the state of the body in norm or pathology. Systems thinking are not only a correct assessment of the interaction of human organs or systems in relation to the environment in health and disease, but also means a systematic approach to prevention (primary, secondary and tertiary), diagnosis, treatment, rehabilitation and integrated health care. it is especially necessary to include in the learning process clinical epidemiology, developing systems thinking, analytical statistics, evidence-based medicine, ISO international standards, ethics and interaction between a doctor and a patient, etc.

It is important to move from subject teaching to subject teaching, to rebuild the technological educational process so that knowledge is not diffused in time and would be purposeful. It is on the problem (and not subject) approach that education in medical schools at universities and colleges in many countries of the world is based on. Their curriculum consists of blocks, the training is multidisciplinary with a large share of independent learning. Postgraduate training includes specialization (professional requirements, training bases, etc.), advanced training and improvement, the latter two being elements of continuing medical education. It is also necessary to provide medical workers with modern information and educational materials at the workplace, including methodological and scientific manuals, etc. according to the profile of work, access to modern educational resources.

The teacher has the ability to build a system of psychological and pedagogical conditions, which not only provides, but also forces any student to act correctly, in the required format and with the specified indicators [3].

Modernization of higher medical education based on innovative teaching methods, its timely and competent change should become a guarantee of the training of a qualified, responsible, independent specialist.

\section{MATERIALS AND METHODS}

Among the works that reveal the structure of the professional activity of a doctor, one should mention, first of all, the works of A.N. Leontiev [11], V.V. Davydov [13], V.V. Rubtsov [14], which show that professional activity, including medical, from the point of view of its structure, has two sides executive (external) and reflective-incentive (internal, mental). The inner side is mental activity directed by the goals, needs and motives of the physician. The external side consists of a number of components, including actions and operations, and is characterized by a certain specificity of their manifestation. The work of N.V. also helps to understand the structure of professional medical activity. N. Kuzmina, dedicated to pedagogical activity. Describing the structure of pedagogical activity, she identified a number of components: gnostic, design, constructive, communicative, organizational, reflexive, perceptual [15]. These components are also present in the activity of a doctor. Analysis of the concept of "professional medical activity" shows that the authors generally agree on the definition of the main structural components of this activity. So, for example, Z.I. Yanushkevichus, describing the activities of a doctor, highlights the stages of collecting anamnesis, research, diagnosis and treatment. I. Hardy identifies similar structures, combining the stages of examination and diagnosis in one stage. V.P. Andronov notes the presence of therapeutic, preventive and diagnostic components of professional medical activity [16].

In scientific research on the professional training of medical workers, the systematic, axiological, activity, competence and other approaches are considered separately (R.I. Aizman, N.N. Aniskina, E.G. Bastrakova, T.K. Bugaeva, I.G. Grekova, O. N. Kolomiets, etc.). The axiological approach focuses on the value aspects of professional activity and preparation for it. The competence-based approach in the professional training of specialists makes it possible to determine the professional competencies and competencies of the future or current specialist in a multi-level and multi-aspect system of training and retraining of medical education.

The activity-based approach allows us to consider the continuous professional training of nurses, doctors and pharmacists as an activity in the unity of its structural 
components. The activity approach is expressed through normativity and variability. In the process of professional training of specialists, normativity is reflected in standards, curricula and academic disciplines. Variability is the realization of the tendency to change what has been achieved for the improvement and development of activities. The integrative and systematic approaches to the training of specialists contribute to the orientation of the process of forming a holistic medical-psychological-pedagogical knowledge, integrative skills of a specialist and the development of new types of activity.

An integrative approach, based on the activity approach as a basis, is associated with a focus on the concepts of "integration" and "activity" and their correlation to the subject of research - continuous professional training of specialists. The study of continuous professional training of specialists from the standpoint of science alone will be limited, incomplete; it requires an interdisciplinary approach. The integrative approach combines the systemic, axiological, competence-based, activity-based and integrative approaches, the integral complex of which makes it possible to most fully reflect the complexity and multidimensionality of the problem under consideration. At the same time, an activity approach (E. I. Artamonova, N. K. Chapaev, M. A. Galaguzova, M. N. Gladkova, S.I. Glukhikh, A. Ya. Danilyuk, V. S. Danyushenkov, O. V. Korshunova, I. M. Osmolovskaya, M. V. Ryzhakov, V. V. Serikov, S. E. Shishov, I. A. Zimnyaya, E. F. Zeer, etc.), multilevel and multicomponent, can be chosen for integration [18]. Integrative analysis should serve the purpose of creating an integrative model for training medical personnel, aimed at enhancing the processes of developing the ability and readiness for self-learning and mutual learning, reflection and design, cognition and metacognition $[19 ; 20$; 21]. The medical worker of the present is only one of the guidelines of such a system, traditions, experience of the past, and the desired image of the medical worker of the future are of no less importance $[22 ; 23 ; 24]$.

The management of the processes and results of the educational and (mastered) professional activity of each student both in the context of general training and in the context of an individual educational trajectory can be carried out using methodological tools (including accumulating their manuals), developed by teachers of pharmacology, histology, anatomy, medical law, etc., based on the model of the indicative basis of mental actions [11].

In the course of our research, students were offered to work with a specially developed by us methodological aids, the purpose of which was to recreate and present to students an indicative basis of action (P.Ya. Galperin, N.F. Talyzina and others and their concept of the phased formation of mental actions) [17]. For each individual subject of research and the skills formed in connection with it, an indicative basis of action was developed and proposed within the framework of special methodological manuals - a system of representations of the subject about the goal, method and conditions for the implementation of the forthcoming or performed action. Some of the tasks were composed in such a way that the students themselves could and should have developed an indicative basis of actions, analyzing their own and others' results of research and work with a specific block of information. As is known in the theory of the phased formation of mental actions, the effectiveness of the indicative basis depends on the degree of community included knowledge (landmarks) and on the completeness of reflection in them of the conditions that determine the success of the action, as well as on the method of obtaining it. This theory also notes the importance and interconnection of the stages of exteriorization and interiorization of actions, as well as knowledge and skills that provide one or another action. Here we turned to the position of the concept that an indicative basis can be given to students both in a finished form and developed by them independently: in the process of applying the "trial and error" method and in the process of consciously applying a more general technique (method) previously obtained independently or from a teacher.

In the course of the study, the authors created and implemented 10 curricula (courses) covering the main disciplines of vocational training in the 3rd year of a medical university. In each of the cases, students were offered a manual aimed at working on the development (interiorization, appropriation) and creation (exteriorization) of the indicative foundations of mental actions. Each manual had 3 options: in the first version, the manual emphasized the processes of assigning ready-made indicative foundations of action, in the second - the development of its own indicative bases, in the third - a combined version was proposed. Thus, the study involved three main subgroups. The study also involved a fourth, control subgroup who was not included in the learning process with the aid. A total of 60 students 20-24 years old took part in the study, including 30 girls and 30 boys. The social profile of students, as well as their age, was quite similar: the children of employees, including 30 children with parents or grandparents who were medical workers, the other 30 were children whose parents and families were actively interested in medical, healing, etc. knowledge and competencies.

Based on the aim and results of the study, a number of questions were formulated and their expert and survey assessment was carried out:

1) have student performance indicators and other external criteria for learning success changed? The answer to this question was obtained by us based on an analysis of the results of academic performance and a survey of the students themselves.

2) have the indicators of interest in learning and future profession changed? The answer to this question was obtained by us on the basis of an analysis of the results of a survey of students;

3) whether the indicators of satisfaction with the learning process have changed. The answer to this question was obtained by us on the basis of an analysis of the results of a 
survey of students;

4) whether the indicators of students' identification with their future profession have changed. The answer to this question was also obtained based on the analysis of the results of a survey of students

5) have students' relationships with each other and with teachers changed? The answer to the last question was also obtained based on the analysis of the results of the survey of students.

A short interview was conducted with the students on the topic: Has your attitude towards yourself and your profession changed during the last year of study? What do you associate this with? Has it affected you and your fellow students' academic performance?

\section{RESULTS}

As a result of our research, it was revealed that the students who participated in the study as the main group (3 subgroups), in contrast to the students of the control group (1 subgroup), significantly increased the indicators (Table1).

Table 1

Survey educational results by subgroups of respondents

\begin{tabular}{|c|c|c|c|c|}
\hline \multirow[t]{2}{*}{ Rate of change } & \multicolumn{3}{|c|}{ Subgroups, main } & \multirow{2}{*}{$\begin{array}{c}\begin{array}{c}\text { subgroup, } \\
\text { control }\end{array} \\
4\end{array}$} \\
\hline & 1 & 2 & 3 & \\
\hline Academic performance & +40 & +47 & +73 & -13 \\
\hline $\begin{array}{l}\text { Interest in training and } \\
\text { future profession }\end{array}$ & +60 & +53 & +93 & -33 \\
\hline $\begin{array}{l}\text { Satisfaction with the } \\
\text { process and learning } \\
\text { outcomes }\end{array}$ & +47 & +33 & +87 & -33 \\
\hline $\begin{array}{l}\text { Identification with the } \\
\text { profession }\end{array}$ & +47 & +67 & +80 & -20 \\
\hline $\begin{array}{l}\text { Identification with the } \\
\text { professional community }\end{array}$ & +67 & +47 & +73 & -40 \\
\hline
\end{tabular}

The assessment of changes in academic performance was carried out by us based on the summation of points in all disciplines of the previous and current year of study. We identified the percentage of students whose academic performance increased or decreased.

The assessment of changes in the motivation of educational activity was carried out in the course of calculating the percentage of students who noted its decrease or increase. The rest of the variables were estimated in a similar way.

There are some results:

1) academic performance. In subgroups numbers 1, 2 and 3, progress and attendance rates increased significantly, especially for the third main subgroup, in which these changes were typical for almost all students. In the first and second subgroups, the growth in academic performance and attendance was pronounced, but less typical (for some students it was relatively weak). In the control subgroup, there was a slight decrease in academic performance among students with little motivation to learn.

2) Interest in training and future profession. As expected, the third year, which was a psychologically turning point in the preparation of many students, brought quite strong differences into the resulting picture: a pronounced increase in motivation to master a profession and study among the main groups, a decrease in motivation among some of the most dissatisfied with education of students in the control group;

3) satisfaction with the process and learning outcomes; Here the picture was generally similar to the previous questions, however, it was noticeable that some of the students of the first and second subgroups were more satisfied with the proposed training option than others. In the third subgroup, the increase in satisfaction with the process and learning outcomes was almost unambiguous; in the fourth subgroup, the indicators of satisfaction with learning decreased in almost all students (which is associated with the crisis of 3 years of study);

4) identification with the profession. As expected, the situation with this indicator was similar to the situation with the previous indicator, the changes were especially pronounced in the third and second subgroups, where students were actively building indicative foundations, independently exploring the field of professional activity.

5) Identification with the professional community. As expected, the situation with the latter indicator turned out to be the situation with indicators of self-identification and satisfaction is close: the changes were especially important in the third and first subgroups, where students were actively building indicative foundations, with the guidance of teachers who introduced them into the semantic field of professional activity.

When assessing the differences in the data obtained by subgroups, a nonparametric method was used to check the equality of the medians of several samples, the N. KruskellWallis test (the Kruskal — Wallis one-way analysis of variance), $\mathrm{a} \mathrm{h}_{\text {empirical }}=16.24161$ was obtained. $=16.24161, \mathrm{p}=$ 0.00101. Accepted H1: the differences between the results of the groups are statistically significant at $\mathrm{p} \leq 0.01$.

When assessing the differences between 3 and 4 subgroups by the $U$ test (Mann-Whitney U-test, which allows us to identify differences in the parameter value between small samples), we obtained: $\mathrm{U}_{\text {empirical }}=0.0, \mathrm{U} 0.01=1.0, \mathrm{U} 0.05=$ 4.0. Thus, $\mathrm{H} 1$ is again adopted: the differences between the results of groups 1 and 2 are statistically significant $\mathrm{p} \leq 0.01$.

In general, we see that traditional teaching, not focused on the use and formation of detailed indicative foundations of action (in an educational dialogue with a teacher, textbook, other students) leads to a loss of interest in education, psychological burnout (de-identification with the profession and study, a decrease in self-satisfaction. and study, to a decrease in academic performance). On the contrary, enhancing the work of students in the context of the application and creation of indicative foundations of actions helps to increase the motivation and quality of education, to overcome the 3-year crisis associated with students' attempts to assess their readiness and ability for professional activity, performing professional actions and solving tasks inherent in activities. 


\section{DISCUSSIONS}

In psychological and pedagogical studies, it is noted that the educational results of students are technically related to the organization of teaching academic disciplines [25], namely, with the main types of teacher's professional activity, affecting the processes of interiorization and exteriorization. knowledge and skills in the learning process [26]: 1) planning, design of future educational results of students in the form of "didactic schemes" for the systemic orientation of students in professional knowledge and skills, [27, p. 17]; 2) the teacher's description of the "manifestations of competences", his understanding of the competencies of a nurse, doctor or pharmacist in the language of labor actions "using an expert approach $[14 ; 28]$, in the form of a competency map; 3 ) the specialist identifies the motives of the upcoming professional activity, comprehends the social and professional situation, 4) reflection, control and self-control, in which the specialist monitors the actions and activities performed by them and the students in different ways, to identify possible mistakes and ways to improve.

To organize the management of educational and research and other types of educational and professional activities of each student in class and distance forms, the teacher must develop special tools [29], for example, study books for a particular discipline. Such notebooks in their structure and content, they model cognitive activity, starting from the phase of motivation and ending with reflection. The teacher himself can be offered a manual for the organization and control of educational and research and other types of student activities within the framework of a particular topic. In such textbooks, it is important to reflect the desirable (optimal), normative and undesirable options for performing educational and research and other professional and educational tasks, typical answers, conclusions, swap tasks, etc. that a student can commit to work with educational and other information.

The psychological significance of such schemes, benefits, etc. consists in the fact that they help the learners and educators of the learner in various educational and professional situations, providing him with educational independence and minimizing the number of mistakes.

The organization of the student's educational and practical activities, in this case, should be aimed at developing his readiness and ability to perform various types and forms of professional activity, due to different social and professional situations and relationships. The teacher manages the processes of interiorization of the exteriorization of the content reflected in individual and generalized schemes and manuals. For this, the student is given various practical educational and professional tasks. So the student performs the activity in the most expanded form, arguing the stages, forms and content of actions in individual and joint work (with the teacher and other students). It is also important to create conditions for students to understand the meaning and values of their educational and professional activities, to correlate them with normative (external) assessment criteria, values and meanings [30].
Thus, different types of professional activities in the process of learning or self-study, following in a certain sequence and reflecting the interaction of internal (mental) and external (physical) actions, constitute intensive training that implements the psychological processes of interiorization and exteriorization in the educational process.

An important aspect of successful educational relations is the harmonization of relations between subjects of education, the prevention and correction of stresses of relationships, including stress of innovation: reactions to changes and innovations in the educational environment, including the processes of digitalization and the globalization of education and culture in general $[31 ; 32 ; 33]$. This can be seen even from the data we obtained: where students had the opportunity to receive indicative bases of action from the teacher and build them independently, satisfaction with learning was the highest, professional identification was successfully formed, relations with teachers were harmoniously formed. Since it is obvious that all the highlighted effects are closely interrelated, it can be said that this also influenced academic performance. It was also clear that the adoption of the new teaching methodology by the students caused the most noticeable positive results where the relations in education were most harmonious. The presence of an indicative basis for action and / or an understanding of the possibility of creating or obtaining it minimized the stress of students. This directed their attention from worries about success and failure, comfort or discomfort of training to the training itself, to professional knowledge and skills. In our study, we did not pay special attention to the changes taking place in terms of students' understanding of digitalization and globalization processes, but overall satisfaction with education, its processes and results, speaks of the success of prevention and overcoming the stresses associated with these concepts as well. Digital literacy, as well as students' understanding of issues of global importance for life, are contexts that can naturally be formed in the course of the general cultural preparation of students with the help of manuals similar to those developed by us, that is, including tasks for application / mastering and isolating / creation of indicative action bases.

Teachers themselves must be ready for innovation, as well as be able to prepare and conduct innovations in education in the practice of interacting with students $[34 ; 35 ; 36 ; 37]$. In the system of higher medical education, requirements for the effectiveness of training and education of future doctors are constantly growing. In these conditions, the development and development of the theory and practice of activity education in a medical college or university from the standpoint of competence, axiological and other approaches, their productive integration to ensure a new stage in the development of medical education seems to be relevant [38; 39; 40]. For the modern stage of development of secondary and higher medical education, a contradiction is characteristic, which consists in the discrepancy between the increasing need for training students, the development of their professional 
competence using the capabilities of the activity approach and the level of development of scientific and applied foundations for solving this problem [41; 42]. The changes that are now taking place in the system of secondary and higher medical education reflect the increased requirements for the effectiveness and productivity of training and education, should be carried out on the basis of an activity-based approach to the organization of the educational process [43; $44 ; 45 ; 46]$.

\section{CONCLUSION}

Taking into account the analysis, the structure of domestic medical education should be brought in line with the requirements of the World Federation of Medical Education, using international experience in this area, with the strengthening of the clinical focus of medical education. Implementation of a system for training medical and pharmaceutical personnel on the basis of international standards, taking into account the priorities and characteristics of Russian healthcare, will ensure the competitiveness of specialists.

Here it is especially necessary: 1) change in the structure and content of training programs for medical and pharmaceutical personnel, 2) changing the principles of selection and admission of citizens to medical educational organizations, 3) change of the quality assessment system, the level of professional and competence and admission to professional activity, 4) introduction of the introduction of accreditation of educational organizations with the involvement of international experts, 5) strengthening the material and technical base medical education organizations, 6) improvement of the legal and regulatory framework medical and pharmaceutical education, 7) the development on the basis of the system-activity approach and the widespread introduction of new methodological approaches and the educational, methodological and other manuals that provide them, ensuring the harmony of the processes of interiorization and externalization of the knowledge, skills, value orientations necessary for a person as a professional, partner and personality.

Some of these tasks can be solved on the basis of ideas and methods created on the basis of the concept of the phased formation of mental actions, similar to those proposed by us, as well as other developments that draw attention to the dynamic and multilateral relationships between external and internal processes in human development.

Many ideas and technologies of the activity approach can make a significant contribution to the development of medical education. The "activity-based approach to learning" is understood as a theory of teaching, based on the activity-based concept of assimilation of social experience, in which: 1) the main goal of teaching is the development of students, providing conditions for self-development; the student is recognized as a subject of the educational process; 2) training involves the organization and management of educational and cognitive activities of students on the basis of cooperation, subject-subject interaction; learning is seen as an activity; 3) the assimilation of knowledge and skills is considered as an active research process carried out through motivated and purposeful problem solving. An activity-based approach is essential for the implementation of the new paradigm of education. It is aimed at organizing active-activity learning with a focus on the development of the personality of students, their mental and creative abilities, creating conditions for selfdevelopment of students, providing a basis for the "launch of mechanisms" for self-learning.

The contribution of our study in comparison with other studies is to develop, test and comprehend the effects of training future physicians in the context of the activity approach, consider the possibilities and prospects of a systematic understanding of the training of medical workers in universities and colleges, as well as the directions of application of the activity model of education and its methods and technologies in educational practice of medical educational institutions. The advantage of our research is the focusing of attention in the theoretical and empirical part of the study on the interaction of the phenomena of exteriorization and interiorization in the training of medical specialist, on the effects that are associated with each of these groups of phenomena in the processes and results of education of future specialists. Our work contributes to the modernization of the higher education system: in science and practice, a lot of explanatory and design models and technologies have already been accumulated that can significantly intensify the processes and increase the educational results of future medical workers. However, until now, medical education remains in this sense little involved in the process of modernization. We tried to change this by using the developments of domestic and foreign scientists who have long demonstrated their productivity and effectiveness in other areas of education. In the future, we plan to include students of different courses and specializations in the study, which will allow us to conduct in-depth comparative studies and develop the most optimal model for training future medical specialists, as well as options for building individual educational trajectories on its basis.

\section{REFERENCES}

[1] S. Mennin "Self-organisation, integration and curriculum in the complex world of medical education". Med Educ. 2010, vol. 44(1), pp. 20-30. https://doi.org/10.1111/j.13652923.2009.03548.x. PMID: 20078753.

[2] V.L. Patel, J.F. Arocha, T. Branch, and D.R. Karlin "Relationship between small group problem-solving activity and lectures in health science curricula". Journal Dent Educ. 2004, vol. 68(10), pp. 1058-1080. PMID: 15466057.

[3] Y. Okuda, E.O. Bryson, S. Jr. DeMaria, L. Jacobson, J. Quinones, B. Shen, AI. Levine. "The utility of simulation in medical education: what is the evidence?" The Mount 
Sinai Journal of Medicine. 2009 , vol. 76(4), pp. 330-43. https://doi.org/10.1002/msj.20127. PMID: 19642147.

[4] M. Valcke, B. De Wever. "Information and communication technologies in higher education: evidence-based practices in medical education". Medical Teacher. 2006, vol. 28(1), pp. 40-48. https://doi.org/ 10.1080/01421590500441927. PMID: 16627322.

[5] M. Srinivasan, D.D. Pratt, J. Collins, C.M. Bowe, F.T. Stevenson, S.J. Pinney, M.S. Wilkes. "Developing the master educator: cross disciplinary teaching scholars program for human and veterinary medical faculty". Academic Psychiatry. 2007; vol. 31(6), pp. 452-464. https://doi.org/10.1176/appi.ap.31.6.452. PMID: 18079507.

[6] G. Greeno, J. "Trends in the theory of knowledge for problem solving".. Problem-Solving and Education. 2010, pp. 9-23.

[7] Kirschner, P., Vilsteren, P., Hummel, H. "The design of a study environment for acquiring academic and professional competence". Studies in Higher Education. 2007, vol. 22 (2), pp. 151-171.

[8] Posner, M. I. and S. W. Keele, "Skill learning". In R. M. W. Travers (ed.), Second Handbook on Research on Teaching, Chicago: Rand McNally Publ., 2003, pp. 805831.

[9] R. M. Gagne, The Conditions of Learning. New York: Holt, Rinehart \& Winston. 2011, pp. 17-29.

[10] F. P. Basso, , \& Abrahão, M. H. M. Barreto. "Atividades de Ensino que Desenvolvem a Autorregulação da Aprendizagem". Educação \& Realidade, 2018, vol. 43(2), pp. 495-512. https://doi.org/10.1590/2175-623665212

[11] A.N. Leontiev. Actividad, Conciencia y Personalidad. Cerrada de San Antonio: Editorial Cartago de Mexico, 1984.

[12] Vygotskiy L. S. Collection . Moscow, 1982. Vol. 2, pp. $1-287$.

[13] V.V. Davydov. Types of generalization in teaching. Moscow: University publ., 1974. (in Russian)

[14] V.V. Rubtsov. The development of the foundations of reflexive thinking of schoolchildren in the process of educational activity. Novosibirsk: University publ., 1985. (in Russian)

[15] N.V. Kuzmina. Research methods of pedagogical activity. Leningrad: University publ., 1970. (in Russian)

[16] V.P. Andronov. Psychological foundations of the formation of professional thinking. Saransk: University publ., 1991. (in Russian)

[17] Galperin, P. Ya. "Psychology of thinking and studies of the gradual formation of mental actions and concepts". Research of the thinking in Soviet psychology. Moscow, 2006, pp.1-249. (In Russian)

[18] Y. Agranovich, A. Amirova, L. Ageyeva, L. Lebedeva, Sh.Aldibekova, E. Uaidullakyzy. "The Formation of SelfOrganizational Skills of Student's Academic Activity on the Basis of 'Time Management' Technology". International Journal of Emerging Technologies in Learning (iJET). 2019, vol. 14, 22, pp. 95-110.
[19] A.W. Astin, H.S. Astin, J.A. \& Lindholm. Cultivating the spirit: How college can enhance students' inner lives. Ney York: John Wiley \& Sons, 2010, pp. 1-240.

[20] R. Azevedo, D. Moos, J. Greene, F., Winters, J. Cromley. "Why is Externally-Facilitated Learning more Effective than Self-Regulated Learning with Hypermedia?" Education Technology Research Development, New York, 2008, vol. 56, pp. 45-72, 2008.

[21] V.V. Gura, I.Y. Lutseva. «The role of the students' selforganization in the development of professionally significant competences ». International Journal of Experimental Education, 2016, vol. 11-2, pp. 149-152.

[22] N. Khanam, «A study on university student's time management and academic achievement ». International Journal of Community Medicine and Public Health, 2017, vol. 4, pp. 4761-4765. https://doi.org/10.18203/23946040.ijcmph20175365

[23] R. Low, P. Jin. "Self-organized Learning". In: Seel N.M. (eds) Encyclopedia of the Sciences of Learning. Springer, Boston, MA, 2012. https://doi.org/10.1007/978-1-4419-1428-6_201

[24] E.A. Railean, G. Walker, A. Elçi and L. Jackson. Handbook of Research on Applied Learning Theory and Design in Modern Education (2 Volumes). New York, London: IGI Global Publ., 2016, pp. 1- 866. https://doi.org/ 10.4018/978-1-4666-9634-1

[25] N.N. Nechaev, "University professor's activity as an evolving process". In: Psychology: psychol. work Moscow psychological social university, Voronezh: MODEK Publ., 2014, pp. 184-205. (In Russian)

[26] Z.A. Reshetova, Psychological activity theory and activity approach to teaching. Formation of system thinking in: Textbook for universities. Moscow: UNITYDANA, 2002, pp. 10-57. (In Russian)

[27] I. I. Ilyasov, N. A. Galatenko, Curriculum scheduling on the subject: guide for teachers. Moscow: Publishing house "Logos", 1994. 208 p. (In Russian)

[28] V. I. Zvonnikov, M. B. Chelyshkova, Education quality certification: competence approach: textbook. Moscow: Universitetskaya Kniga. 2009. 272 p. (In Russian)

[29] V.L. Patel, N.A. Yoskowitz, J.F. Arocha. "Towards effective evaluation and reform in medical education: a cognitive and learning sciences perspective". Adventures of the Health Sci Educ Theory Pract. 2009, vol. 14(5), pp. 791-812. https://doi.org/10.1007/s10459-007-9091-1.

[30] N. Abdelkhalek, A. Hussein, T. Gibbs, H. Hamdy. "Using team-based learning to prepare medical students for future problem-based learning." Medical Teaching. 2010, vol. 32(2), $\quad$ pp. 123-9. https://doi.org/10.3109/01421590903548539. PMID: 20163227.

[31] M.R. Arpentieva, Akademicheskoye sotsial'nopsikhologicheskoye obrazovaniye $=$ Academic social and psychological counseling in education. Kaluga: Tsiolkovskiy Kaluga state university, 2015. (In Russian)

[32] M. R. Arpentieva, I. V. Gorelova, K. G. Kassymova, S. V. Lavrinenko, K. A. Shumova, D. M. Malinichev, V. L. 
Simonov, A. V. Kosov, G. V. Garbuzova, O. P. Stepanova, "Human resource management and dynamic capabilities of educational enterprises: psychological, social and economical aspects", Bulletin of the National Academy of Sciences of the Republic of Kazakhstan,2020, vol. 1, 383 (2020), $\quad$ pp. $242 \quad-\quad 254$. https://doi.org/10.32014/2020.2518-1467.30

[33] A.A. Badalov, S.N. Brovkina, M.R. Arpentieva, S.S. Kalinin, G.K. Kassymova , "The Archetype of Intellectual Activity: A Modern Methodology for the Description of the Protophenomenon", Klinicheskaia $i$ spetsial'naia psikhologiia $=$ Clinical Psychology and Special Education, 2020, vol. 9(1), pp. 1-16. https://doi.org/10.17759/cpse.2020090101

[34] G. K. Kassymova, S. V. Lavrinenko, E. R. Kraynova, R. R. Gasanova, E. N. Kamenskaya, A. V. Kosov, M. R. Arpentieva, I. V. Gorelova, "Modern concepts and archetypes of the management in education: psychological, social and economical aspects". Bulletin of the National Academy of Sciences of the Republic of Kazakhstan,2020, vol. 2, 384 (2020), pp. 194 - 204. https://doi.org/10.32014/2020.2518-1467.59

[35] K. G. Kassymova, G. V. Valeeva, O.P. Stepanova, O.A. Goroshchenova, R.R. Gasanova, Kulakova A. A., Menshikov P.V., Arpentieva M. R., Garbuzova G.V. Stress of the innovation and innovations in education. Bulletin of National Academy of Sciences of the Republic of Kazakhstan. 2019, vol. 6, pp. 278-289.

[36] B.M. Triyono, N. Mohib, G.K. Kassymova, G.N.I.P. Pratama, D. Adinda, M.R. Arpentieva. "The Profile Improvement of Vocational School Teachers' Competencies". Vysshee obrazovanie v Rossii = Higher Education in Russiam 2020, vol. 29(2), pp. 151-158. https://doi.org/10.31992/0869-3617-2020-29-2-151-158

[37] O. B. Kenzhaliyev, Zh. B. Ilmaliyev, B. M. Triyono, A. D. Minghat, M. R. Arpentieva, G. K. Kassymova, “ Commercialization of Research and Development Results as the Economy Growth Factor of the Republic of Kazakhstan". International Journal of Advanced Science and Technology, 2020, vol. 29(7s), pp. 18 - 28. Retrieved from

http://sersc.org/journals/index.php/IJAST/article/view/941 0 (accessed 10.10.2020)

[38] N. Shmurygina, N. Bazhenova, R. Bazhenov., N. Nikolaeva, and A. Tcytcarev. "Self-Organization Activities of College Students: Challenges and Opportunities". International journal of environmental \& science education, 2016, vol. 11, 17 pp., 9981-9989

[39] J.H. Muller, D.M. Irby. "Developing educational leaders: the teaching scholars program at the University of California, San Francisco, School of Medicine". Academic Medicine. 2006, vol. 81(11), pp. 959-64. doi: 10.1097/01.ACM.0000242588.35354.db. $\quad$ PMID: 17065856.

[40] A.Z. Frohna, S.J. Hamstra, P.B. Mullan, L.D. Gruppen. "Teaching medical education principles and methods to faculty using an active learning approach". Academic Medicine. 2006, vol. 81(11), pp. 975-8. doi:
10.1097/01.ACM.0000242573.71314.74.

PMID:

17065859.

[41] M. Srinivasan, S.T. Li, F.J. Meyers, D.D.Pratt, J.B. Collins, C. Braddock, K.M. Skeff, D.C. West, M. Henderson, R.E. Hales, D.M. Hilty. "Teaching as a Competency": competencies for medical educators". Academic Medicine. 2011, vol. 86(10), pp. 1211-20. https://doi.org/10.1097/ACM.0b013e31822c5b9a. PMID: 21869655.

[42] M.M. Batova, I. V. Baranova, "Information Technology Knowledge Management in the System of Interaction of Educational and Scientific-Production Structures", WSEAS Transactions on Business and Economics, 2019, vol. 16, pp. 545-551.

[43] S.E. Carr, S.J. Miller, Z.S. Siddiqui, D.R. Jonas-Dwyer. Enhancing Capabilities in health professions education". International Journal of the Medical Education. $2015 \mathrm{Nov}$ 22; 6, pp.161-5. https://doi.org/10.5116/ijme.5641.060c. PMID: 26590857; PMCID: PMC4662867.

[44] L. Y. Kusi, H.A. Domfeh, P.Kim, "Impact of celebrity advertising on purchase intention of University Students: The moderating role of celebrity advertising risk", WSEAS Transactions on Business and Economics, 2018, vol. 15, pp. 128-142.

[45] V.L. Patel, N.A. Yoskowitz, J.F. Arocha, E.H. Shortliffe. "Cognitive and learning sciences in biomedical and health instructional design: A review with lessons for biomedical informatics education". Journal of the Biomedical Information. 2009 , vol. 42(1), pp. 176-97. https://doi.org/10.1016/j.jbi.2008.12.002..

[46] - S.K. Zia. "Teaching as a competency: practical suggestions". Academic Medicine, 2012, vol. 87(5), pp. 551. https://doi.org/10.1097/ACM.0b013e31824d5656. PMID: 22531585.

Contribution of individual authors to the creation of a scientific article:

Conceptualization, Vladimir I. Torshin and Mariam R. Arpentieva.

Methodology, Vladimir I. Torshin and Mariam R. Arpentieva.

Investigation, Vladimir I. Torshin, Dmitriy S. Sveshnikov, Elena B. Yakunina, Zarina V. Bakaeva, Yuri P. Starshinov, Olga V. Mankaeva, Tatiana V. Kivlenok.

Resources, Vladimir I. Torshin, Mariam R. Arpentieva, Dmitriy S. Sveshnikov, Elena B. Yakunina, Zarina V. Bakaeva, Yuri P. Starshinov, Olga V. Mankaeva, Tatiana V. Kivlenok;

Writing-Original Draft Preparation, Elena B. Yakunina, Zarina V. Bakaeva, Olga V. Mankaeva;

Writing-Review \& Editing, Vladimir I. Torshin, Dmitriy S. Sveshnikov, Yuri P. Starshinov Tatiana V. Kivlenok ;

Supervision, Vladimir I. Torshin, and Mariam R. Arpentieva.

Project Administration, Vladimir I. Torshin, and Mariam R. Arpentieva.

All authors contributed to the study conception and design. All authors performed material preparation, data collection 
and analysis. Vladimir I. Torshin and Mariam R. Arpentieva wrote the first draft of the manuscript and all authors commented on previous versions of the manuscript. All authors read and approved the final manuscript.

V.I. Torshin, is with the Medical Institute Peoples' Friendship University of Russia, Dr.Hab. in Biology, Head at the Department of normal physiology, Moscow, 117198, Russian Federation, email: vtorshin@mail.ru; ORCID ID 0000-0002-3950-8296 (second corresponding author to provide phone: 74954331022; e-mail: vtorshin@mail.ru).

D. S. Sveshnikov is with the Medical Institute Peoples' Friendship University of Russia, Moscow, Dr. Hab. in Medicine, Associate professor at the Department of normal physiology, Medical Institute, Russian Federation, 117198, email: dmsveshnikov@gmail.com. ORCID ID 0000-00017795-0897

E. B. Yakunina, is with the Medical Institute Peoples' Friendship University of Russia, $\mathrm{PhD}$ in Medicine, Associate professor at the Department of normal physiology, Moscow, 117198, Russian federation, email: dr.yakunina@gmail.com, ORCID ID 0000-0002-7962-1971

Z.V. Bakaeva is with the Medical Institute Peoples' Friendship University of Russia, Assistant at the Department of normal physiology, Moscow, 117198, Russian Federation. E-mail: bakaeva_zv@mail.ru, ORCID ID 0000-0001-7795 0897

Y.P. Starshinov is with the Medical Institute Peoples' Friendship University of Russia, PhD in Medicine, Associate professor at the Department of normal physiology, Moscow, 117198, Russian Federation. Email: 1345301@mail.ru, ORCID ID 0000-0002-1836-6209

O. V. Mankaeva is with the Medical Institute Peoples' Friendship University of Russia, $\mathrm{PhD}$ in Medicine, Associate professor at the Department of normal physiology, Moscow, 117198, Russia, email: mankaeva_ov@pfur.ru

M.R. Arpentieva* is with the Center for Psychological, Pedagogical, Medical and Social Assistance "Assistance", head of the scientific department, Dr.Hab. in Psychology, associate professor, Kaluga, 248000, Russian Federation, email: mariam_rav@mail.ru; ORCID ID: 0000-0003-32494941, (second corresponding author to provide phone: +79533134816; e-mail: mariam_rav@mail.ru)

T.V. Kivlenok is with the M.M. Speranskiy Law Institute, A.G. and N.G. Stoletovs Vladimir State University, Head of the Department of Civil Law and Procedure, PhD in Law (Candidate of Legal Sciences), Associate Professor, Vladimir, 600005, Russian Federation, e-mail: ta-bagi@mail.ru, ORCID ID: 0000-0002-8137-5466

\section{Creative Commons Attribution License 4.0 (Attribution 4.0 International, CC BY 4.0)}

This article is published under the terms of the Creative Commons Attribution License 4.0

https://creativecommons.org/licenses/by/4.0/deed.en_US 